\title{
DEPTH RETRIEVAL FROM A RESERVOIR USING A CONDITIONAL-BASED MODEL
}

\author{
Melina Brunelli Nunes ${ }^{1}$, Aluir Porfírio Dal Poz ${ }^{1}$, Enner Alcântara ${ }^{1}$, Marcelo Curtarelli ${ }^{2}$ \\ ${ }^{1}$ São Paulo State University (UNESP), Brazil \\ ${ }^{2}$ Federal University of Santa Catarina (UFSC), Brazil
}

KEY WORDS: bathymetry, Landsat-8, Lyzega, dam, accuracy, Amazonian region, multispectral sensor.

\begin{abstract}
:
Water depth is an important measure for nautical charts. Accurate methods to provide water depth information are expensive and time costing. For this reason, since late 70's, it started to be estimate by multispectral sensors with empirical models. In the literature there is no investigation using empirical models partitioned in depth intervals, for this reason, we evaluated the accuracy of partitioned and single bathymetric models. The results have shown that to retrieve depth in from 0 to $15 \mathrm{~m}$ the single model provided an RMSE of $3.57 \mathrm{~m}$, with a bias of about $-0.83 \mathrm{~m}$; while the RMSE for the partitioned model was $2.29 \mathrm{~m}$ with a bias of $0.41 \mathrm{~m}$. For updating nautical charts using multispectral sensors it was concluded that the partitioned model can provide a better result than using a single model.
\end{abstract}

\section{INTRODUCTION}

Accurate water depth measurement is an important parameter in aquatic system, since this information could be used e.g to make or update nautical charts to support navigation, explain the amount of deposit sediments, and manage and monitor areas close to water system. Nowadays the most common techniques to provide bathymetric information are echosounders and airborne laser bathymetry. Although these methods are accurate, they are also expansive and time consuming. For this reason, in the last decades, Remote Sensing techniques have been used to acquire depth in shallow water from multispectral and hyperspectral sensors (Lyzenga,1978; Stumpf et al., 2003, Dierssen et al., 2003; Pacheco et al., 2015; Kerr, Purkis, 2018; Brando et al.,2009).

Firstly, the depth retrieval using multispectral sensors used a linear regression model that can estimate water depth in a specific area with clear and shallow waters (Lyzenga, 1978). Subsequently, different empirical methods to derivate the depth from multispectral sensors were proposed (Stumpf et al, 2003; Dierssen et al., 2003, Pacheco et al.,2015; Kabiri, 2017). In the late 90's, Lee et al. (1999) proposed a physical-based approach for depth estimation, in which remote sensing reflectance $\left(\mathrm{R}_{\mathrm{rs}}\right)$ was a function of water columns and water bottom. This approach generally uses hyperspectral sensors (Lee et al., 1999; Brando et al., 2009). A simpler physical-based approach was created by Lyzenga et al. (2006) that can estimate the water depth independently of the ground truth.

Most recently, strategies including empirical and physics-based approach started retrieving depth using multispectral imagery without ground truth data (Kerr, Purkis, 2018). The Kerr and Purkis (2018) method, use a library of several spectra benthic substrate to find the bottom reflectance which is going to be used as input on empirical model, producing an accurate depth retrieval up to $12 \mathrm{~m}$ deep. Also using empirical models, Traganos et al (2018) compared different algorithm using Google Earth Engine to find the Lyzenga's methods as being the most accurate one. To support the Lyzenga et al. (2006) technique, Manessa et al. (2018) prove that the absence of ground-truth does not have a great influence on the estimated depth for shallow waters.

Although optical bathymetry shows accurate results, it still has some limitations, presenting low accuracy in deep and turbid waters. This limitation is due to light attenuation in the water column, which has suspended and dissolved material interacting with light radiation. In general, the detectable depth is around $20 \mathrm{~m}(\mathrm{Gao}, 2009)$ and in clear waters it can reach an accuracy of about five times better than in turbid waters (Pan, 2015). This limitation makes it difficult to estimate the depth on deep waters such as oceans, rivers, lakes and dams. Dams are mostly turbid due to the organic material flooded, especially on the Amazon region. Because of the high turbid waters and the difficulty to accomplish field surveys, few studies have been made in this region.

The aim of this paper is to apply Lyzengas's empirical method in turbid and shallow water in the Amazon region using the multispectral sensor OLI (Operation Land Imager) onboard of the satellite Landsat-8. For a more accurate modeling, instead of using a single regression model for the whole region, the area was partitioned in three parts. One part corresponds to depths ranging from $0 \mathrm{~m}$ to $5 \mathrm{~m}$, the second part ranges from $5 \mathrm{~m}$ to $10 \mathrm{~m}$, and the last one ranges from $10 \mathrm{~m}$ to $15 \mathrm{~m}$. Finally, in order to assess the accuracy of both bathymetry procedures, corresponding results are presented and analyzed.

\section{METHODOLOGY}

\subsection{Study area}

This investigation focuses on the Tucuruí Hydroeletric Reservoir (THR) (Figure 1), located on northeast of Pará State, Brazil, in the Amazon region. This reservoir was implanted along the Tocantins river and to starts its operations in 1984 a vast area of native tropical forest was flooded. Nowadays the dam floods $2,290 \mathrm{~km}^{2}$ during the dry season and can reach 
$2,850 \mathrm{~km}^{2}$ during the wet season with $126 \mathrm{~km}$ of extension reaching seven cities.

THR has several side effects, such as loss of forest, decrease of water quality, displacement of residents in the flooded area (including indigenous people), greenhouse gas emission, decrease of fish downstream and mosquito breeding ground (Fearnside, 2000). This dam is one of the biggest hydroelectric plant in Brazil, generating a total of 8,370 MWh.

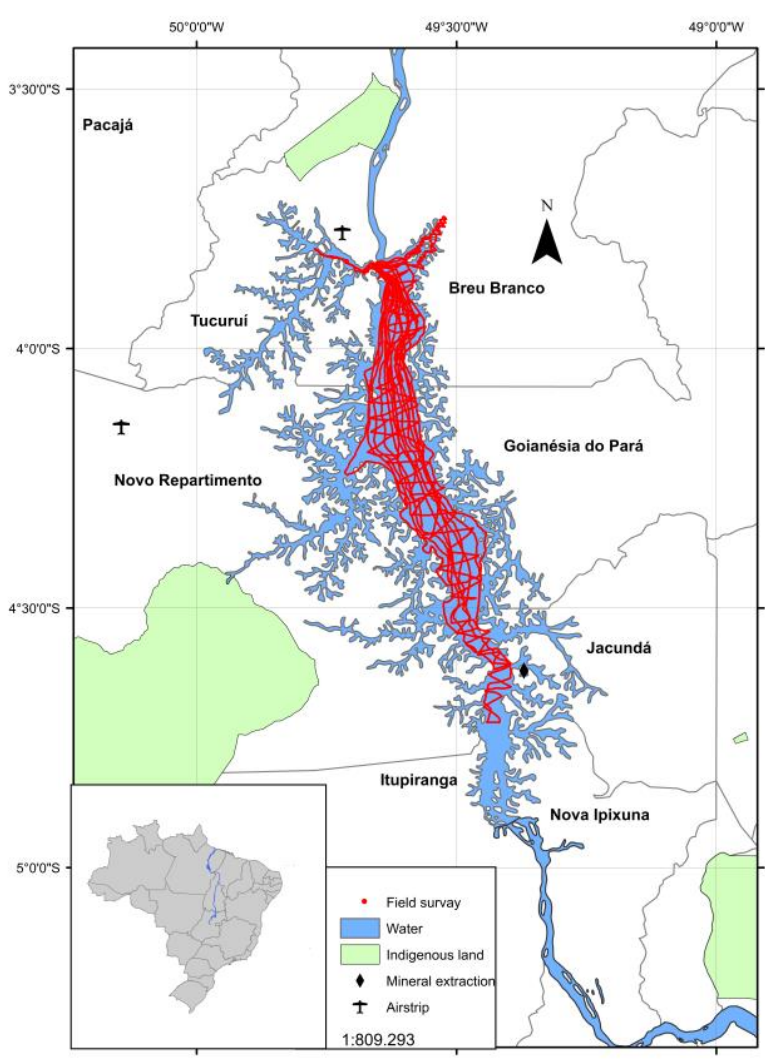

Figure 1. Location of study area: THR

\subsection{Dataset}

The sensor Operational Land Images (OLI) onboard the satellite Landsat- 8 has 9 spectral bands, but only four were used in this research: costal blue $(0.435-0.451 \mu \mathrm{m})$, blue $(0.452-$ $0.512 \mu \mathrm{m})$, green $(0.533-0.590 \mu \mathrm{m})$ and red $(0.636-$ $0.673 \mu \mathrm{m}$ ) with $30 \mathrm{~m}$ of spatial resolution. The United States Geological Survey (USGS) provides for the Landsat-Collection a surface reflectance $\left(R_{\text {sur }}\right)$ product, generated by using the Land Surface Reflectance Code (LaSRC). This product was proved to be suitable for aquatic application (Bernardo, 2017, Wei et al., 2018). The OLI image was acquired on July $18^{\text {th }}, 2013$ near the date that the field survey was accomplished.

The field survey was accomplished by Curtarelli (2015) from July $3^{\text {rd }}$ to July $16^{\text {th }} 2013$. The depth samples used the ecobathymeter model GPSmap 520s Garmin ${ }^{\circledR}$ (Olathe, KS, USA) with vertical accuracy of $\pm 0.1 \mathrm{~m}$. The route is shown in Figure 1, covering a total of $2,600 \mathrm{~km}^{2}$ with 179,898 depth samples.

\subsection{Interpolation}

Curtarelli et al. (2015) showed that the best interpolation method for this area is the Ordinary Kriging (Isaaks, Srivastava,
1989). We use as weight to this interpolation the spherical semivariogram model.

\subsection{Cloud and shadow exclusion}

The Landsat- 8 metadata provides image quality assessment (QA) that exposes the clouds and their respective shadows (Scaramuzza et al., 2012). With this image we can remove the pixels that do not have water surface information by applying a mask with QA image.

\subsection{Remote sensing reflectance}

Remote sensing reflectance $\left(\mathrm{R}_{\mathrm{rS}}\right)$ is a crucial propriety for water application, such as the determination of water depth and bottom composition. $\mathrm{R}_{\mathrm{rs}}$ is defined as (Mobley, 1999):

$$
\mathrm{R}_{\mathrm{rs}}(\theta, \varphi, \lambda)=\mathrm{L}_{\mathrm{w}}(\theta, \varphi, \lambda) / \mathrm{E}_{\mathrm{d}}(\lambda)
$$

Where $\theta$ is the zenithal angle, $\varphi$ is the azimuthal angle, and $\lambda$ is the wavelength. $\mathrm{L}_{\mathrm{w}}(\theta, \varphi, \lambda)$ is the water-leaving reflectance in the $(\theta, \varphi)$ direction and $\mathrm{E}_{\mathrm{d}}(\lambda)$ is the downwelling irradiance. The water-leaving reflectance (a.k.a. marine reflectance) is defined as (Ruddick et al., 2006):

$$
\rho_{\mathrm{w}}(\theta, \varphi, \lambda)=\pi \mathrm{L}_{\mathrm{w}}(\theta, \varphi, \lambda) / \mathrm{E}_{\mathrm{d}}(\lambda)
$$

Therefore:

$$
\mathrm{R}_{\mathrm{rs}}(\theta, \varphi, \lambda)=\rho_{\mathrm{w}}(\theta, \varphi, \lambda) / \pi
$$

The $\rho_{\mathrm{w}}(\theta, \varphi, \lambda)$ is, in other words, the $\mathrm{R}_{\text {sur }}$ for the water pixel, that can be estimated from atmospheric correction using the USGS product LaSRC.

\subsection{Depth retrieval algorithm}

One of the most popular depth retrieval algorithms that uses multispectral images was developed by Lyzenga (1978) (Pacheco et al, 2015; Kabiri, 2017). This algorithm uses linear regression to estimate the values of depth. Our computational implementation is based Lyzenga's equation, as follows:

$$
Z=a_{o}+a_{i} x_{i}+a_{j} x_{j}+a_{k} x_{k}+a_{1} x_{l}
$$

Where:

$$
\mathrm{X}_{\mathrm{i}}=\ln \left(\mathrm{R}_{\mathrm{rs}, \mathrm{i}}-\mathrm{R}_{\mathrm{rs}, \infty \mathrm{i}}\right)
$$

In equations (4) and (5): $\mathrm{Z}$ is the water depth; $\mathrm{R}_{\mathrm{rs}, \infty \mathrm{i}}$ is the reflectance value of deep water; and $\mathrm{a}_{0}, \mathrm{a}_{\mathrm{i}}, \mathrm{a}_{\mathrm{j}}, \mathrm{a}_{\mathrm{k}}$, and $\mathrm{a}_{1}$ are constants that should be determined using multiple linear regression and subscripts $o, i, j, k$ and 1 mean different spectral bands. Initially the equation (4) was used for only two bands, however, studies (Pacheco et al, 2015; Kabiri, 2017) have shown that three bands provide better results.

In this research, we applied equations (4) and (5) for depths ranging from $0 \mathrm{~m}$ to $15 \mathrm{~m}$, i.e., a single model is firstly used for depth retrieval. We also applied these equations for partitioned depth intervals, as follows: one for depths ranging from $0 \mathrm{~m}$ to $5 \mathrm{~m}$, another for depths ranging from $5 \mathrm{~m}$ to $10 \mathrm{~m}$, and the last one for depths ranging from $10 \mathrm{~m}$ to $15 \mathrm{~m}$. This generates three different equation that applied to the respective intervals generate three different surface modeling, thus allowing a potentially better approximation of the whole bottom surface. 


\section{RESULTS}

\subsection{Interpolation}

The interpolation method used in this research is the ordinary kriging, using spherical semivariogram model to determinate the weights (Isaaks, Srivastava, 1989). As a result of the interpolation model, we obtained an RMSE $=2.22 \mathrm{~m}$ and a bias $=0.036$.

Figure 2 shows the result of the cross-validation procedure, which compares the ground truth measured on the field with the ordinary kriging interpolation. The maximum difference between the measure and the predicted depths is about $50 \mathrm{~m}$ and the minimum is $0 \mathrm{~m}$.

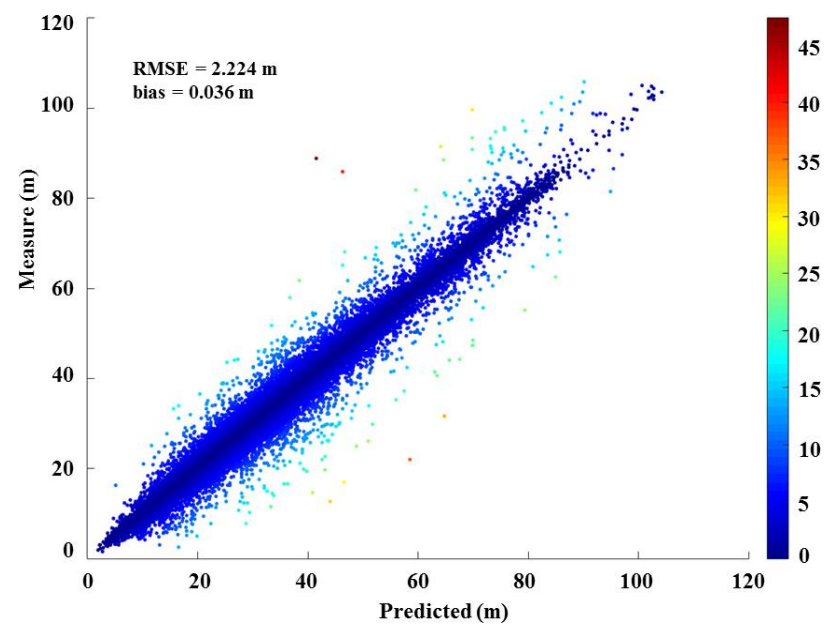

Figure 2. Scatter-plot of predicted and measure depths of the Ordinary Kriging

\subsection{Depth retrieval algorithm}

Appling the Lyzenga's empirical method to the study area, using the single model for shallow waters $(0-15 \mathrm{~m})$, we obtained a good accuracy $(\mathrm{RMSE}=3.57 \mathrm{~m})$ considering that this region has turbid water. For better understanding, the statistical analysis was divided into classes of $5 \mathrm{~m}$ (Table 1). The partitioned model was also applied to this test area, resulting a lower correlation for Class 2 and $3\left(\mathrm{R}^{2}=0.50\right.$ and $\mathrm{R}^{2}=0.36$ respectively) than in the single model $\left(\mathrm{R}^{2}=0.63\right)$. Although, all partitioned models produce lower RMSE than the single model as shown in the Table 1.

The RMSE can be five times higher for the single model, losing accuracy in some regions. The bias in the partitioned models is smaller for all classes while the single model exceeds $1 \mathrm{~m}$ in two out of three classes. The major unconformity is shown in the interval between $0-5 \mathrm{~m}$, showing a standard deviation three times bigger in the single model and bias eleven times higher.

Figure 3 shows two profiles (A and B) for the ground truth depth and for the depths derived from the partitioned and single models. Note that the partitioned model profile follows the ground truth profile, while the single model seems to have less variation in depth, maintaining almost the same range along the profiles (between 10 and $15 \mathrm{~m}$ ).

\section{DISCUSSION}

Several authors have advised that the maximum depth that can be estimated using multispectral sensor is about $20 \mathrm{~m}$ (Gao, 2009; Pacheco et al., 2015; Kabiri, 2017). It is not possible to predicted higher depths by using multispectral sensors due to the interactions that occur with the incident light in the water with the molecules and the optically significant components present in this system.

In comparison to the other researches, as in Kabiri (2017) and Pachceco et al. (2015), the results obtained in this paper using the single model shows to be two and three times less accurate, respectively. However, the turbidity in the test area is higher. Using a single model, the interval between $0-5 \mathrm{~m}$ with RMSE= $4.75 \mathrm{~m}$, shows to be the highest in this research. That occurs due to the high value of the independent constant found in the regression $\left(\mathrm{a}_{0}=22.11\right)$ and the small values of the other constants. When the model was applied to the whole area, it tended to show high values of depth. Contrary to what might be expected, unlike band 2 , band 4 contributes significantly with the model. That is probably because the area has inorganic components, responding to the red wavelength.

In pursuit of improvement in the depth retrieval, this research separates the area between 0 to $15 \mathrm{~m}$ in three sections $(0-5 \mathrm{~m}, 5$ $10 \mathrm{~m}$, and $10-15 \mathrm{~m}$ ), thereby is calculate three different regression models for the area. The first interval shows great correlation $\left(\mathrm{R}^{2}=0.80\right)$ between the measured and the predicted depths and the lowest RMSE (RMSE $=0.89 \mathrm{~m}$ ). Even though the other models do not have a satisfactory correlation $\left(\mathrm{R}^{2}=0.50\right.$
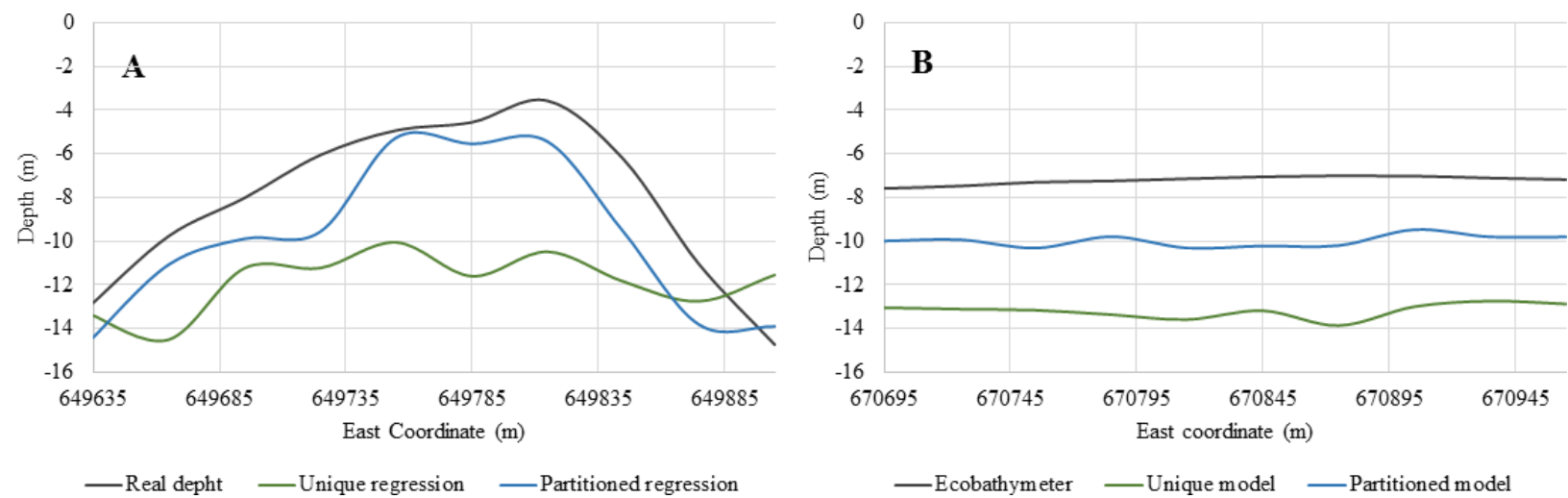

Figure 3. Profiles spaced by 30 m extracted by the ecobathymeter, the single model and the partitioned model 


\begin{tabular}{|c|c|c|c|c|}
\hline \multicolumn{5}{|c|}{ Multiple linear regression - single } \\
\hline Interval: $0-15 \mathrm{~m}$ & $Z_{\text {LSat8 }}=22.11-4.16$ & $\mathrm{X}_{\mathrm{B}}+11.87 \mathrm{X}_{\mathrm{G}}-5.82 \mathrm{X}_{\mathrm{R}}$ & $\mathrm{R}^{2}=0.63$ & \\
\hline Residual Statistics & \begin{tabular}{l|l|} 
& Class 1 \\
& $0-5 \mathrm{~m}$ \\
\end{tabular} & $\begin{array}{l}\text { Class 2 } \\
5-10 \mathrm{~m} \\
\end{array}$ & $\begin{array}{l}\text { Class } 3 \\
10-15 \text { m } \\
\end{array}$ & $\begin{array}{l}\text { Overall } \\
0-15 \text { m }\end{array}$ \\
\hline Num & 4,262 & 66,213 & 224,144 & 294,619 \\
\hline Std (m) & 2.00 & 1.96 & 2.74 & 2.69 \\
\hline $\operatorname{Var}(\mathrm{m})$ & 3.99 & 3.85 & 7.52 & 7.24 \\
\hline $\operatorname{Max}(\mathrm{m})$ & 21.67 & 26.29 & 30.94 & 30.94 \\
\hline $\operatorname{Min}(\mathrm{m})$ & -1.74 & -37.95 & -33.84 & -37.95 \\
\hline Dif_mean (bias) (m) & 4.25 & 0.95 & -1.46 & -0.83 \\
\hline Dif_median $(\mathrm{m})$ & 3.67 & 0.06 & -1.07 & -0.86 \\
\hline RMSE $(\mathrm{m})$ & 4.72 & 2.51 & 3.80 & 3.57 \\
\hline \multicolumn{5}{|c|}{ Multiple linear regression - partitioned } \\
\hline Interval: $0-5 \mathrm{~m}$ & \multicolumn{2}{|c|}{$Z_{-L S a t 8}=-3.87-2.09 \mathrm{X}_{\mathrm{CB}}-1.46 \mathrm{X}_{\mathrm{B}}+3.16 \mathrm{X}_{\mathrm{G}-0.93 \mathrm{X}_{\mathrm{R}}}$} & \multicolumn{2}{|l|}{$\mathrm{R}^{2}=0.80$} \\
\hline Interval: $5-10 \mathrm{~m}$ & \multicolumn{2}{|c|}{$\mathrm{Z} \_$LSat8 $_{1}=14.17+5.11 \mathrm{X}_{\mathrm{CB}}-8.68 \mathrm{X}_{\mathrm{B}}+8.19 \mathrm{X}_{\mathrm{G}-3.13 \mathrm{X}_{\mathrm{R}}}$} & \multicolumn{2}{|l|}{$\mathrm{R}^{2}=0.50$} \\
\hline Interval: $10-15 \mathrm{~m}$ & \multicolumn{2}{|c|}{$\mathrm{Z}_{\mathrm{L} S \mathrm{~L} \text { t8 }}=3.07+6.91 \mathrm{X}_{\mathrm{CB}}-18.19 \mathrm{X}_{\mathrm{B}}+11,65 \mathrm{X}_{\mathrm{G}}-1,57 \mathrm{X}_{\mathrm{R}}$} & \multicolumn{2}{|l|}{$\mathrm{R}^{2}=0.36$} \\
\hline Residual Statistics & \begin{tabular}{l|l|} 
& Class 1 \\
& $0-5 \mathrm{~m}$ \\
\end{tabular} & $\begin{array}{l}\text { Class } 2 \\
5-10 \mathrm{~m}\end{array}$ & $\begin{array}{l}\text { Class 3 } \\
10-15 \text { m }\end{array}$ & $\begin{array}{l}\text { Overall } \\
0-15 \text { m }\end{array}$ \\
\hline Num & 4,262 & 66,213 & 224,144 & 294,619 \\
\hline Std (m) & 0.65 & 1.02 & 1.66 & 2,57 \\
\hline $\operatorname{Var}(\mathrm{m})$ & 0.42 & 1.04 & 2.76 & 6,58 \\
\hline $\operatorname{Max}(\mathrm{m})$ & 10.22 & 20.44 & 52.33 & 52,33 \\
\hline $\operatorname{Min}(\mathrm{m})$ & 0.27 & -25.62 & -27.86 & $-27,86$ \\
\hline Dif_mean (bias) (m) & -0.38 & 0.23 & 0.48 & 0.41 \\
\hline Dif_median $(\mathrm{m})$ & -0.42 & -0.32 & 0.38 & 0.85 \\
\hline RMSE (m) & 0.89 & 1.61 & 2.48 & 2.29 \\
\hline
\end{tabular}

Table 1. Coefficients and residual statistics derived from single and partitioned linear regression between remote sensing reflectance and ecobathymeter depth.

and $\mathrm{R}^{2}=0.36$ respectively), the RMSE of those models are better than the RMSE of the single model.

It is also necessary to consider the error introduced by the interpolation model, which can lead to erroneous results in depth retrieval. The error of the interpolation is probably due to the lack of information on the borders of the reservoir, causing a bad estimative in this area.

\section{CONCLUSIONS}

After the applications of Lyzenga's model to THR, it was verified that the single regression model is not able to explain all the depth accurately. As expected, the partitioned regression models showed a better result, since the depth intervals are smaller. The disadvantage of the partitioned model is that the application of equations requires as input multispectral images and depth information to determinate the domains of all regression.

\section{REFERENCES}

Brando, V. E., Anstee, J. M., Wettle, M., Dekker, A. G., Phinn, S. R., \& Roelfsema, C., 2009. A physics based retrieval and quality assessment of bathymetry from suboptimal hyperspectral data. Remote Sensing of Environment, 113(4), 755-770. doi.org/10.1016/j.rse.2008.12.003

Bernardo, N., Watanabe, F., Rodrigues, T., \& Alcântara, E., 2017. Atmospheric correction issues for retrieving total suspended matter concentrations in inland waters using OLI/Landsat-8 image. Advances in Space Research, 59(9), 2335-2348. doi.org/10.1016/j.asr.2017.02.017
Curtarelli, M., Leão, J., Ogashawara, I., Lorenzzetti, J., \& Stech, J., 2015. Assessment of spatial interpolation methods to map the bathymetry of an Amazonian hydroelectric reservoir to aid in decision making for water management. ISPRS International Journal of Geo-Information, 4(1), 220-235. doi.org/10.3390/ijgi4010220

Dierssen, H. M., Zimmerman, R. C., Leathers, R. A., Downes, T. V., \& Davis, C. O., 2003. Ocean color remote sensing of seagrass and bathymetry in the Bahamas Banks by high-resolution airborne imagery. Limnology and oceanography, 48(1part2), 444-455. doi.org/10.4319/lo.2003.48.1_part_2.0444

Explorer, U. E. (2010). Available online: http://earthexplorer. usgs.gov.

Fearnside, P. M., 1999. Social impacts of Brazil's Tucuruí dam. Environmental Management, 24(4), 483-495. doi.org/10.1007/s002679900248

Gao, J., 2009. Bathymetric mapping by means of remote sensing: methods, accuracy and limitations. Progress in Physical Geography, 33(1), 103-116. doi.org/10.1177/0309133309105657

Guide, P., 2018. Landsat 8 surface reflectance code (LaSRC) product. Availabe online: https://landsat.usgs.gov/sites/default/files/documents/lasrc_prod uct_guide.pdf

Isaaks, E. H., \& Srivastava, R. M., 1989: An introduction to applied geostatistics. Oxford University Press. New York, USA. 
Kabiri, K., 2017. Accuracy assessment of near-shore bathymetry information retrieved from Landsat-8 imagery. Earth Science Informatics, 10(2), 235-245. doi.org/10.1007/s12145-017-0293-7

Kerr, J. M., \& Purkis, S., 2018. An algorithm for opticallyderiving water depth from multispectral imagery in coral reef landscapes in the absence of ground-truth data. Remote sensing of environment, $\quad 307-324$. doi.org/10.1016/j.rse.2018.03.024

Lee, Z., Carder, K. L., Mobley, C. D., Steward, R. G., \& Patch, J. S., 1999. Hyperspectral remote sensing for shallow waters: 2 . Deriving bottom depths and water properties by optimization. Applied optics, 38(18), 3831-3843. doi.org/10.1364/AO.38.003831

Lyzenga, D. R., 1978. Passive remote sensing techniques for mapping water depth and bottom features. Applied optics, 17(3), 379-383. doi.org/10.1364/AO.17.000379

Lyzenga, D. R., Malinas, N. P., \& Tanis, F. J., 2006. Multispectral bathymetry using a simple physically based algorithm. IEEE Transactions on Geoscience and Remote Sensing, 44(8), doi.org/10.1109/TGRS.2006.872909

Manessa, M. D. M., Kanno, A., Sagawa, T., Sekine, M., \& Nurdin, N., 2018. Simulation-based investigation of the generality of Lyzenga's multispectral bathymetry formula in Case-1 coral reef water. Estuarine, Coastal and Shelf Science, 200, 81-90. doi.org/10.1016/j.ecss.2017.10.014

Mobley, C. D. (1999). Estimation of the remote-sensing reflectance from above-surface measurements. Applied optics, 38(36), 7442-7455. doi.org/10.1364/AO.38.007442

Pacheco, A., Horta, J., Loureiro, C., \& Ferreira, Ó., 2015. Retrieval of nearshore bathymetry from Landsat 8 images: A tool for coastal monitoring in shallow waters. Remote Sensing of Environment, 159, 102-116. doi.org/10.1016/j.rse.2014.12.004

Pan, Z., Glennie, C., Hartzell, P., Fernandez-Diaz, J., Legleiter, C., \& Overstreet, B., 2015. Performance assessment of high resolution airborne full waveform LiDAR for shallow river

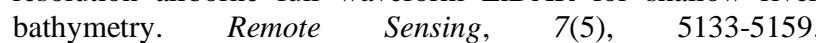
doi.org/10.3390/rs70505133

Ruddick, K. G., De Cauwer, V., Park, Y. J., \& Moore, G. (2006). Seaborne measurements of near infrared water-leaving reflectance: The similarity spectrum for turbid waters. Limnology and Oceanography, 51(2), 1167-1179. doi.org/10.4319/lo.2006.51.2.1167

Scaramuzza, P. L., Bouchard, M. A., \& Dwyer, J. L. (2011). Development of the Landsat data continuity mission cloudcover assessment algorithms. IEEE Transactions on Geoscience and Remote Sensing, 50(4), 1140-1154. doi.org/10.1109/TGRS.2011.2164087

Stumpf, R. P., Holderied, K., \& Sinclair, M., 2003. Determination of water depth with high-resolution satellite imagery over variable bottom types. Limnology and Oceanography, 48(1part2), 547-556. doi.org/10.4319/lo.2003.48.1_part_2.0547
Traganos, D., Poursanidis, D., Aggarwal, B., Chrysoulakis, N., \& Reinartz, P., 2018. Estimating satellite-derived bathymetry (SDB) with the google earth engine and sentinel-2. Remote Sensing, 10(6), 859. doi.org/10.3390/rs10060859

Wei, J., Lee, Z., Garcia, R., Zoffoli, L., Armstrong, R. A., Shang, Z., ... \& Chen, R. F., 2018. An assessment of Landsat-8 atmospheric correction schemes and remote sensing reflectance products in coral reefs and coastal turbid waters. Remote sensing of environment, 215, 18-32. doi.org/10.1016/j.rse.2018.05.033 